\title{
Helmet CPAP revisited in COVID-19 pneumonia: A case series
}

\author{
Aniket S. Rali ${ }^{1}$, Christopher Howard ${ }^{1}$, Rachel Miller ${ }^{2}$, Christopher K. Morgan ${ }^{1}$, \\ Dennis Mejia ${ }^{3}$, John Sabo ${ }^{3}$, James P. Herlihy', Sunjay R. Devarajan ${ }^{1}$
}

\begin{abstract}
A. S. Rali, C. Howard, R. Miller, C. K. Morgan, D. Mejia, J.Sabo, J. P. Herlihy, S. R. Devarajan. Helmet CPAP revisited in COVID-19 pneumonia: A case series. Can J Respir Ther 2020;56:32-34. doi: 10.29390/cjrt-2020-019.

Introduction: Noninvasive positive pressure ventilation (NIPPV) plays an important role in the management of respiratory failure. However, since the emergence of the COVID-19 pandemic, utilization of traditional face mask NIPPV has been curtailed in part due to risk of aerosolization of respiratory particles and subsequent health care worker exposure. A randomized clinical trial in 2016 reported that an alternative interface, helmet NIPPV, may be more effective than traditional NIPPV at preventing intubation and improving mortality. The helmet NIPPV interface provides positive airway pressure, while also theoretically minimizing aerosolization, making it a feasible modality in management of respiratory failure in COVID-19 patients.

Case and outcomes: This report describes a single-center experience of a series of three COVID-19 patients with hypoxemic respiratory failure managed with helmet NIPPV. One patient was able to avoid intubation while a second patient was successfully extubated to NIPPV. Ultimately, the third patient was unable to avoid intubation with helmet NIPPV, although the application of the device was late in the progression of the disease.

Discussion: NIPPV is an important modality in the management of respiratory failure and has been shown to reduce the need for immediate endotracheal intubation in select populations. For patients unable to tolerate facemask NIPPV, the helmet provides an alternate interface. In COVID-19 patients, the helmet interface may reduce the risk of virus exposure to health care workers from aerosolization. Based on this experience, we recommend that helmet NIPPV can be considered as a feasible option for the management of patients with COVID-19, whether the goal is to prevent immediate intubation or avoid post-extubation respiratory failure. Randomized studies are needed to definitively validate the use of helmet NIPPV in this population.

Conclusion: Helmet NIPPV is a feasible therapy to manage COVID-19 patients.
\end{abstract}

Key Words: continuous positive airway pressure; CPAP; bilevel positive airway pressure; BiPAP; non-invasive positive pressure ventilation; NIPPV; NIV helmet; COVID19; SARS-COV2

\section{INTRODUCTION}

Acute hypoxemic respiratory failure is a known complication of severe acute respiratory infections such as severe acute respiratory syndrome (SARS) [1, 2], pandemic 2009 influenza A (H1N1) [3], Middle East respiratory syndrome (MERS) [4], and now pandemic Coronavirus disease 2019 (COVID-19) [5, 6]. Noninvasive positive pressure ventilation (NIPPV) plays an important role in the management of acute respiratory failure and the prevention of post-extubation respiratory failure in select populations including those with cardiogenic pulmonary edema and chronic obstructive pulmonary disease (COPD) [7, 8]. However, traditional NIPPV delivered by facemask can lead to significant health care worker exposure to aerosolization of infectious respiratory pathogens [9].

Due to the risk of aerosolization, the safety of traditional NIPPV use during the COVID-19 pandemic has been debated [10]. Prior to the onset of COVID-19, a single-center randomized control trial demonstrated that an alternate interface, helmet NIPPV, may be superior to traditional NIPPV in preventing intubation and improving mortality rate in patients with hypoxemic respiratory failure [11]. The helmet interface also reduces the risk of particle aerosolization [11]. Further, reports from Italy and China indicated that COVID-19 patients managed with helmet NIPPV can have favorable outcomes; however, these benefits have not yet been confirmed in a randomized control trial
$[12,13]$. This report summarizes the clinical course of three confirmed COVID-19 patients with hypoxemic respiratory failure managed at a single center with helmet NIPPV.

IRB approval for this project was formally waived by the institution as the sample size was less than 4 patients.

Case 1

A 54-year-old female with no significant past medical history presented to an outside hospital with progressively worsening symptoms of fever, cough, shortness of breath, and pleuritic chest pain. A chest radiograph revealed bilateral airspace disease. Given significant tachypnea and hypoxemia on presentation, she was intubated and mechanically ventilated. Nasopharyngeal viral polymerase chain reaction testing isolated SARS-CoV2, confirming the diagnosis of severe COVID-19 infection. The patient was urgently transferred to our hospital. Her admission arterial blood gas (ABG) showed pH 7.42, $\mathrm{PCO}_{2}$ $40 \mathrm{mmHg}$, and $\mathrm{PaO}_{2} 111 \mathrm{mmHg}$ with a $\mathrm{PaO}_{2} / \mathrm{FiO}_{2}$ ratio (P/F) 222 that worsened to a nadir of 95 at the peak of illness. The patient remained intubated for a total of 16 days before being extubated to helmet NIPPV. The ventilator settings were an inspiratory positive airway pressure (IPAP) of $10 \mathrm{cmH}_{2} \mathrm{O}$, expiratory positive airway pressure (EPAP) of $5 \mathrm{cmH}_{2} \mathrm{O}$, and $\mathrm{FiO}_{2}$ of $60 \%$. An $\mathrm{ABG}$ obtained after 2 hours of helmet NIPPV use were $\mathrm{pH} 7.49, \mathrm{PCO}_{2} 42 \mathrm{mmHg}, \mathrm{PaO}_{2}$

\footnotetext{
${ }^{1}$ Section of Pulmonary, Critical Care and Sleep Medicine, Department of Internal Medicine, Baylor College of Medicine, Houston, TX, USA

${ }^{2}$ School of Medicine, Baylor College of Medicine, Houston, TX, USA

${ }^{3}$ Department of Respiratory Care, Baylor St. Luke's Medical Center, Houston, TX, USA

Correspondence: Christopher Howard, MD, 7200 Cambridge Street, A 10 189, BCM 903, Houston, Texas 77030, USA; Tel: 832-729-1184. Email: Christopher. howard@bcm.edu
}

Published online at https://www.cjrt.ca on 23 July 2020 
$184 \mathrm{mmHg}$, and $\mathrm{PaO}_{2} / \mathrm{FiO}_{2}$ of 307. Treatment with helmet NIPPV was continued for a total of 24 hours and the patient was subsequently weaned off to low-flow nasal cannula.

\section{Case 2}

A 42-year-old female with a past medical history of hypertension and obesity presented to an outside hospital with symptoms of fever, cough, and shortness of breath worsening over a 4 -day period. Chest radiography revealed bilateral airspace disease. The patient was admitted due to respiratory distress. Testing isolated SARS-CoV2, and over the next 4 days, the patient developed progressive hypoxemic respiratory failure and was transferred to our hospital. On arrival, the patient's oxygen saturation was $90 \%$ while receiving nasal oxygen at $5 \mathrm{~L}$ per minute with a respiratory rate of 32 breaths per minute and increased work of breathing on physical exam. An ABG showed $\mathrm{pH} 7.38, \mathrm{PCO}_{2} 40 \mathrm{mmHg}$, and $\mathrm{PaO}_{2} 54 \mathrm{mmHg}$. The decision was made to place her on helmet NIPPV with IPAP of $18 \mathrm{cmH}_{2} \mathrm{O}$, EPAP of $12 \mathrm{mmH}_{2} \mathrm{O}$ and $\mathrm{FiO}_{2}$ of $50 \%$. An ABG after approximately 4 hours of helmet NIPPV treatment was as follows: $\mathrm{pH} 7.42, \mathrm{PCO}_{2} 35 \mathrm{mmHg}$, and $\mathrm{PaO}_{2} 66 \mathrm{mmHg}$ with $\mathrm{FiO}_{2}$ of $50 \%$ for a $\mathrm{PaO}_{2} / \mathrm{FiO}_{2}$ of 132 . Her work of breathing improved after 12 hours of treatment, but the patient reported poor tolerance with this interface, so helmet NIPPV was discontinued and the patient was safely transitioned back to low-flow nasal $\mathrm{O}_{2}$ and transferred out of the intensive care unit.

\section{Case 3}

A 65-year-old female with past medical history of COPD, hypertension, type 2 diabetes mellitus, and obesity presented to an outside hospital with 1 week of acutely worsening shortness of breath associated with fever and cough. Testing isolated SARS-CoV2, and the patient was emergently transferred to our medical center for management of acute hypoxemic respiratory failure. The patient was initially placed on highflow nasal cannula with an $\mathrm{ABG}$ showing $\mathrm{pH} 7.43, \mathrm{PaCO}_{2} 30 \mathrm{mmHg}$, $\mathrm{PaO}_{2} 90 \mathrm{mmHg}$ on $\mathrm{FiO}_{2}$ of $80 \%$ for a $\mathrm{PaO}_{2} / \mathrm{FiO}_{2}$ 113. The patient's respiratory status continued to worsen, requiring $\mathrm{FIO}_{2}$ of $100 \%$ without significant improvement in oxygenation. Helmet NIPPV was started with IPAP of $15 \mathrm{cmH}_{2} \mathrm{O}$, EPAP of $5 \mathrm{cmH}_{2} \mathrm{O}$ and $\mathrm{FiO}_{2}$ of $100 \%$. Despite this change in management, the patient's oxygenation deteriorated further, and she was intubated and mechanically ventilated.

\section{DISCUSSION}

As previously stated, NIPPV is an important modality in the management of respiratory failure and has been shown to reduce the need for immediate endotracheal intubation in select populations [14]. It is also considered standard of care to mitigate post-extubation respiratory failure in high-risk patients especially with underlying COPD and heart failure [15]. NIPPV is most often delivered using a face mask and the evidence to support its benefit in COPD exacerbations and cardiogenic pulmonary edema is well established $[16,17]$. However, it has been reported that some patients, for various reasons, do not tolerate the application of traditional NIPPV by facemask [18]. In addition, there is significant concern about the exposure of health care workers to aerosolized viral pathogens when providing NIPPV with a facemask. These factors create a need for an alternative interface for NIPPV. A past report indicated that NIPPV was not well suited for supporting patients with H1N1 viral pneumonia [19]. Questionable efficacy and the risk of aerosolization have curtailed the use of NIPPV early in the COVID-19 pandemic. However, our institutional experience with COVID-19 patients with respiratory failure indicates that the helmet is a feasible alternate to the facemask interface. The helmet interface achieves the dual objective of providing NIPPV while also minimizing aerosolization [20-22].

In terms of pre-COVID reports on helmet NIPPV, a single-center, non-blinded randomized control trial of 83 patients with acute respiratory distress syndrome requiring NIPPV demonstrated the advantages of the helmet interface compared with facemask delivered NIPPV. The report showed a reduction in intubation rates (absolute difference, $-43.3 \%$; $95 \%$ CI, $-62.4 \%$ to $-24.3 \%$; $P<0.001$ ) as well as 90 -day mortality (absolute difference, $-22.3 \%$; 95\% CI, -43.3 to $-1.4 ; P=0.02$ ) with helmet NIPPV [11]. Patients supported with helmet NIPPV demonstrated significantly improved functional independence (50\% vs. $15.4 \%$; $p=0.001) 1$ year after hospital discharge [11]. Patients in the helmet NIPPV group were also mobilized more reliably in the intensive care unit, experienced less delirium, and encountered less neuromuscular weakness on hospital discharge [11]. The prevention of functional and neuromuscular complications in the helmet group may be explained by the avoidance of immobility and deep sedation practices that may be associated with invasive mechanical ventilation.

With respect to the device itself, helmet NIPPV is delivered via a unique helmet interface (Figure 1) made of transparent latex-free polyvinyl chloride and is secured by attaching two padded armpit straps to hooks on the front and back of a plastic ring. This ring contains a silicone neck seal, which provides the ability to apply positive pressure [22]. The patient's neck circumference is measured, and the neck seal is cut to ensure a tight but comfortable fit. We connected the helmet to a Hamilton Medical G5 or C1 and Philips V60 Respironics ventilators. Ventilator circuitry was either single or double limb (single limb is shown in Figure 1), and viral filters were attached to all exhalation circuitry.

A well-fitted helmet with a snug neck seal essentially eliminates air leak, allows for maintenance of positive pressure in the helmet [22], and therefore minimizes aerosolization [11]. However, given the highly contagious nature of COVID-19, we still recommend patients undergoing HNIV be treated with full respiratory and contact isolation precautions in negative pressure rooms. While there may be a theoretical reduction in risk of disease transmission with use of the helmet interface, there are no data to support this assumption.

While helmet NIPPV has not been extensively validated for its safety and efficacy in COVID-19 patients, our case series demonstrates that it's

\section{FIGURE 1}

\section{Illustration of how the helmet noninvasive positive pressure ventilation (NIPPV) fits over a patient.}

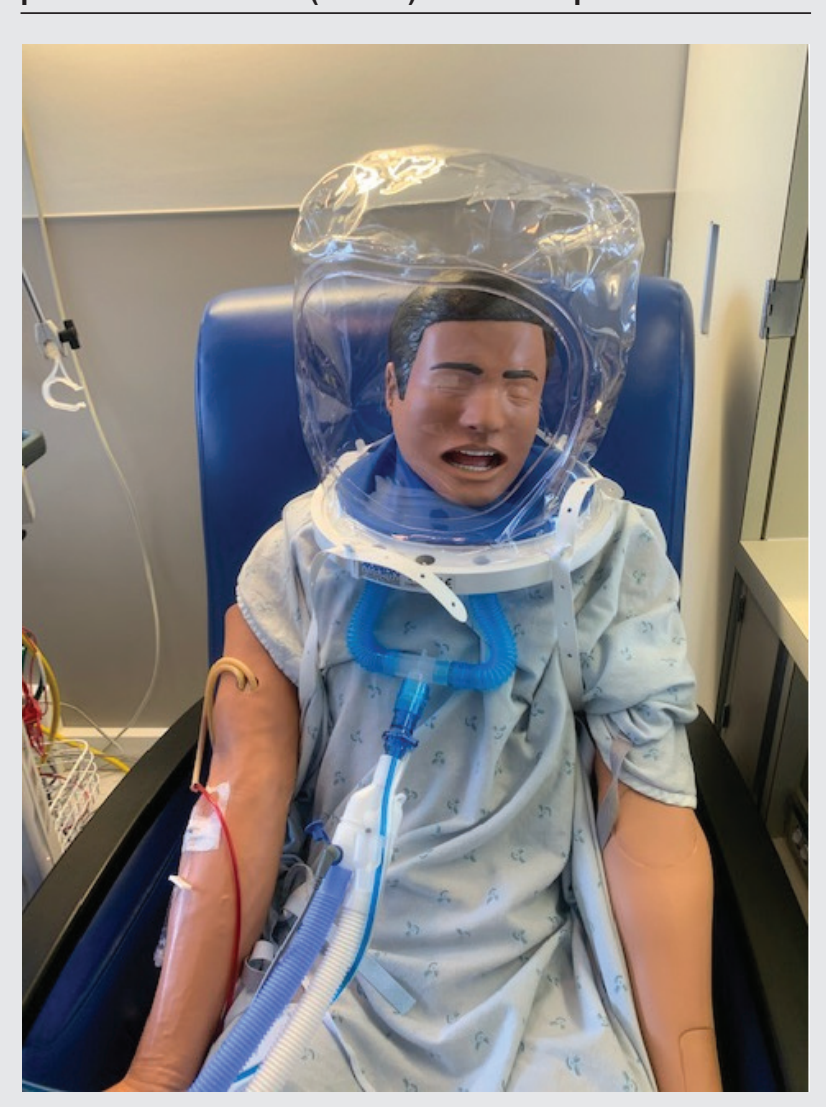


use is feasible. One patient was able to avoid intubation while a second patient was able to be successfully extubated to NIPPV. Ultimately, the third patient was unable to avoid intubation with helmet NIPPV, although the application of the helmet was late in the progression of the disease. Randomized controlled studies are lacking to compare helmet NIPPV with other modalities such as the traditional facemask NIPPV and high-flow nasal cannula in the COVID-19 population.

Among the potential hazards and limitations of using helmet NIPPV is rebreathing exhaled air resulting in hypercapnia. To avoid this, high flow rates (typically $50 \mathrm{~L}$ per minute minimum) are needed to maintain the preset IPAP and EPAP pressure support levels, and appropriate ventilation [23]. The intolerance of the helmet NIPPV system experienced by the patient in Case 2 centered upon her inability to rest her head inside the helmet. We have successfully used neck pads to improve physical comfort and tolerance. Another potential concern with the use of helmet NIPPV is eye or ear barotrauma from the positive pressure ventilation; however, no such complications were reported in a large study evaluating this interface [11]. The experience in our cohort was similar. Frequent application of artificial tears may further help mitigate the risk of corneal aberrations from constant high flow. Furthermore, helmet NIPPV is more equivalent to CPAP, and we would recommend that it is not well suited for patients experiencing significant hypercapnia.

\section{CONCLUSION}

Based on our experience and results, we recommend that helmet NIPPV be considered as a feasible option for the management of patients with respiratory failure due to COVID-19 infection. Utilization of a higher EPAP up to a maximum of $10-12 \mathrm{~cm} \mathrm{H}_{2} \mathrm{O}$, in addition to increased neck support and a better-fitted neck seal may render the maximum benefit of the helmet NIPPV.

\section{Contributors}

All authors contributed to the conception or design of the work and the acquisition, analysis, or interpretation of the data. All authors were involved in drafting and commenting on the paper and have approved the final version.

\section{Funding}

This study did not receive any specific grant from funding agencies in the public, commercial, or not-for-profit sectors.

\section{Competing interests}

All authors have completed the ICMJE uniform disclosure form at www.icmje.org/coi_disclosure.pdf and declare no financial relationships with any organizations that might have an interest in the submitted work in the previous 3 years or no other relationships or activities that could appear to have influenced the submitted work.

\section{REFERENCES}

1. Lee $\mathrm{N}$, et al. A major outbreak of severe acute respiratory syndrome in Hong Kong. N Engl J Med 2003;348(20):1986-94. doi: 10.1056/ NEJMoa030685.

2. Hui DS, Sung JJ. Treatment of severe acute respiratory syndrome. Chest 2004;126(3):670-4. doi: 10.1378/chest.126.3.670.

3. Hui DS, Lee N, Chan PK. Clinical management of pandemic 2009 influenza $A(H 1 N 1)$ infection. Chest 2010;137(4):916-25. doi: 10.1378/ chest.09-2344.
4. Hui DS, Memish ZA, Zumla A. Severe acute respiratory syndrome vs. the Middle East respiratory syndrome. Curr Opin Pulm Med 2014;20(3): 233-41. doi: 10.1097/MCP.0000000000000046.

5. Zhou F, et al. Clinical course and risk factors for mortality of adult inpatients with COVID-19 in Wuhan, China: a retrospective cohort study. Lancet 2020;395(10229):1054-62. doi: 10.1016/S0140-6736(20)30566-3.

6. Namendys-Silva SA. Respiratory support for patients with COVID-19 infection. Lancet Respir Med 2020;8(4):e18. doi: 10.1016/S2213-2600 (20)30110-7.

7. Arabi Y, et al. The critically ill avian influenza A (H5N1) patient. Crit Care Med 2007;35(5):1397-403. doi: 10.1097/01.CCM.0000262940. 34596.4B.

8. Hui DS. Influenza A/H5N1 infection: other treatment options and issues. Respirology 2008;13 Suppl 1:S22-6. doi: 10.1111/j.1440-1843. 2008.01250.x.

9. Hui DS, et al. Noninvasive positive-pressure ventilation: an experimental model to assess air and particle dispersion. Chest 2006;130(3):730-40. doi: 10.1378/chest.130.3.730.

10. Bhatraju PK, et al. Covid-19 in critically ill patients in the Seattle region case series. N Engl J Med 2020. doi: 10.1056/NEJMoa2004500.

11. Patel BK, et al. Effect of noninvasive ventilation delivered by helmet vs face mask on the rate of endotracheal intubation in patients with acute respiratory distress syndrome: a randomized clinical trial. JAMA 2016;315(22):2435-41. doi: 10.1001/jama.2016.6338.

12. Lucchini A, et al. The "helmet bundle" in COVID-19 patients undergoing non invasive ventilation. Intensive Crit Care Nurs 2020:102859. doi: 10.1016/j.iccn.2020.102859.

13. Radovanovic D, et al. Helmet CPAP to treat acute hypoxemic respiratory failure in patients with COVID-19: a management strategy proposal. J Clin Med 2020;9(4). doi: 10.3390/jcm9041191.

14. Rochwerg B, et al. Official ERS/ATS clinical practice guidelines: noninvasive ventilation for acute respiratory failure. Eur Respir J 2017;50(2). doi: 10.1183/13993003.02426-2016.

15. Krishna B, Sampath S, Moran JL. The role of non-invasive positive pressure ventilation in post-extubation respiratory failure: an evaluation using meta-analytic techniques. Indian J Crit Care Med 2013;17(4):253-61. doi: 10.4103/0972-5229.118477.

16. Brochard L, et al. Noninvasive ventilation for acute exacerbations of chronic obstructive pulmonary disease. N Engl J Med 1995;333(13): 817-22. doi: 10.1056/NEJM199509283331301.

17. Vital FM, Ladeira MT, Atallah AN. Non-invasive positive pressure ventilation (CPAP or bilevel NPPV) for cardiogenic pulmonary oedema. Cochrane Database Syst Rev 2013;(5):CD005351. doi: 10.1002/14651858. CD005351.pub3.

18. Schwartz AR, Kacmarek RM, Hess DR. Factors affecting oxygen delivery with bi-level positive airway pressure. Respir Care 2004;49(3):270-5.

19. Namendys-Silva SA, Hernandez-Garay M, Rivero-Sigarroa E. Non-invasive ventilation for critically ill patients with pandemic H1N1 2009 influenza A virus infection. Crit Care 2010;14(2):407. doi: 10.1186/cc8883.

20. Melot C. Contribution of multiple inert gas elimination technique to pulmonary medicine. 5. Ventilation-perfusion relationships in acute respiratory failure. Thorax 1994;49(12):1251-8. doi: 10.1136/thx.49. 12.1251.

21. Corbridge TC, et al. Adverse effects of large tidal volume and low PEEP in canine acid aspiration. Am Rev Respir Dis 1990;142(2):311-5. doi: 10.1164/ajrccm/142.2.311.

22. Hui DS, et al. Exhaled air dispersion during noninvasive ventilation via helmets and a total facemask. Chest 2015;147(5):1336-43. doi: 10.1378/ chest.14-1934.

23. Taccone $\mathrm{P}$, et al. Continuous positive airway pressure delivered with a "helmet": effects on carbon dioxide rebreathing. Crit Care Med 2004;32(10):2090-6. doi: 10.1097/01.CCM.0000142577.63316.C0. 